\title{
The significance of exosomal RNAs in the development, diagnosis, and treatment of pancreatic cancer
}

\author{
Zheng Zhao, Guiping Zhao*, Shuyue Yang, Shengtao Zhu, Shutian Zhang and Peng Li* ${ }^{*}$
}

\begin{abstract}
Exosomes are single-membrane, secreted organelles with a diameter of 30-200 nm, containing diverse bioactive constituents, including DNAs, RNAs, proteins, and lipids, with prominent molecular heterogeneity. Extensive studies indicate that exosomal RNAs (e.g., microRNAs, long non-coding RNAs, and circular RNAs) can interact with many types of cancers, associated with several hallmark features like tumor growth, metastasis, and resistance to therapy. Pancreatic cancer ( $\mathrm{PaCa}$ ) is among the most lethal cancers worldwide, emerging as the seventh foremost cause of cancer-related death in both sexes. Hence, revealing the specific pathogenesis and improving the clinical diagnosis and treatment process are urgently required. As the study of exosomes has become an active area of research, the functional connections between exosomes and PaCa have been deeply investigated. Among these, exosomal RNAs seem to play a significant role in the development, diagnosis, and treatment of PaCa. Exosomal RNAs delivery ultimately modulates the various features of $\mathrm{PaCa}$, and many scholars have interpreted how exosomal RNAs contribute to the proliferation, angiogenesis, migration, invasion, metastasis, immune escape, and drug resistance in PaCa. Besides, recent studies emphasize that exosomal RNAs may serve as diagnostic and prognostic biomarkers or therapeutic targets for $\mathrm{PaCa}$. In this review, we will introduce these recent insights focusing on the discoveries of the relationship between exosomal RNAs and $\mathrm{PaCa}$, and the potentially diagnostic and therapeutic applications of exosomes in $\mathrm{PaCa}$.
\end{abstract}

Keywords: Exosome, Exosomal RNAs, Pancreatic cancer, Biomarker

\section{Background}

Pancreatic cancer $(\mathrm{PaCa})$ is among the most common and devastating malignancies worldwide. Globally, there were reported cases 495,773 and reported deaths 466,003 from $\mathrm{PaCa}$ in 2020, with approximately as many deaths as cases due to its poor prognosis; it ranks, the seventh foremost cause of cancer-related death for both sexes [1]. $\mathrm{PaCa}$ is one of the highest case-fatality cancer types among all solid tumors, as the 5-year survival rate is only $10 \%[2,3]$. The poor prognosis of $\mathrm{PaCa}$ may be attributed

*Correspondence: zhaoguiping@ccmu.edu.cn; lipeng@ccmu.edu.cn Department of Gastroenterology, Beijing Friendship Hospital, Capital Medical University, No. 95 Yong'an Road, Xicheng District, Beijing 100050, China to several factors, including a lack of typical symptoms, difficulties in early diagnosis, high metastatic potential, and resistance to conventional treatment. $\mathrm{PaCa}$, which has no significant symptoms in the early stage, is commonly caught late, which causes a delay in treatment $[4$, 5]. In particular, existing methods, including surgical techniques, chemotherapy, radiation, and immunotherapy, each faces its own challenges, such as recurrence after resection, resistance to chemotherapy and radiation, and uncertainty whether the immunotherapy can be effective for the individual $[6,7]$. Hence, it is urgently needed to identify the specific pathogenesis mechanism and facilitate early diagnosis.

(c) The Author(s) 2021. This article is licensed under a Creative Commons Attribution 4.0 International License, which permits use, sharing, adaptation, distribution and reproduction in any medium or format, as long as you give appropriate credit to the original author(s) and the source, provide a link to the Creative Commons licence, and indicate if changes were made. The images or other third party material in this article are included in the article's Creative Commons licence, unless indicated otherwise in a credit line to the material. If material is not included in the article's Creative Commons licence and your intended use is not permitted by statutory regulation or exceeds the permitted use, you will need to obtain permission directly from the copyright holder. To view a copy of this licence, visit http://creativeco mmons.org/licenses/by/4.0/. The Creative Commons Public Domain Dedication waiver (http://creativecommons.org/publicdomain/ zero/1.0/) applies to the data made available in this article, unless otherwise stated in a credit line to the data. 


\section{Introduction to exosomes}

Exosomes, first recognized in the 1980s by Trams et al., are single-membrane, secreted organelles with a diameter of 30-200 nm $[8,9]$. Exosomes are membrane-bound extracellular vesicles (EVs) that are produced in the endosomal compartment of most eukaryotic cells. Exosomes contain diverse bioactive constituents, including mRNAs, non-coding RNAs (ncRNAs), proteins, and lipids, with prominent molecular heterogeneity [10-13]. Exosomes are originate from double invagination of the membranes of plasma and endosome, and this process is a dedicated mechanism that refers to protein selection, RNA packaging, and EV release [14]. Endosomes form at the plasma membrane or the Golgi, which are membrane-delimited intracellular transport carriers. Once released, exosomes can extend a new paradigm of cell-to-cell communication by transferring those cargoes from donor cells to recipient cells [15]. It is widely documented exosomes are associated with both normal physiology and acquired pathological activities, including but not limited to reproduction, immunity, infection, and tumors [16-19]. As for tumor development, exosomes have diverse activities, such as formation of the tumor microenvironment (TME), initiation, proliferation, angiogenesis, and metastasis [20-22]. Furthermore, the molecular heterogeneity of exosomes has been observed among cancer patients and healthy individuals, and the cargoes and the amounts of exosomes created by the same cell may be dramatically different if educated with different treatments [23-25]. In theory, the heterogeneity of tumor cell-derived exosomes (TDEs) allows them to fulfill diagnostic functions. Cargoes of TDEs, such as microRNAs (miRNAs), long RNAs (lncRNAs), and circular RNAs (circRNAs), have been detected in $\mathrm{PaCa}$ and become novel non-invasive biomarkers for $\mathrm{PaCa}[26,27]$. Moreover, exosomes are emerging as therapeutic tools in several diseases, including $\mathrm{PaCa}[28,29]$. Therefore, we will summarize the biological activities of exosomal RNAs in the initiation and development of $\mathrm{PaCa}$, and introduce the potential clinical applications of exosomes in PaCa.

\section{Formation, secretion, and uptake of exosomes (Fig. 1)}

Exosomes are nanosized EVs enriched in specific nucleic acids, lipids, proteins, and glycoconjugates [30]. Overall, exosomes originate from the first invagination of the plasma membrane, giving rise to early endosomes, and the sequential engulfment of cytoplasmic contents to form multivesicular bodies (MVBs). MVBs are named for their appearance, with a specialized subset of endosomes that contain many small vesicles inside the larger body. After fusion with plasma membrane, MVBs are released as intraluminal vesicles (ILVs) [31, 32]. First, the invagination of the cell membrane forms the early endosome, and in this process, the extracellular fluids and constituents (e.g., proteins, lipids, and other metabolites) can be internalized into the early endosome and the cell membrane proteins. Next, MVBs are derived from the subsequent inward invagination of the endosomal membrane, allowing cytoplasmic components to be engulfed into the endosomes and enrich the cargoes of ILVs. Endosomes are membrane-delimited intracellular transport carriers. Three main endosome compartments exist: early, late, and recycling endosomes. Early endosomes mature into late endosomes that subsequently fuse with lysosomes. Recycling endosomes are a sub-compartment of early endosomes that return material to the plasma membrane. Endosomes form at the plasma membrane or the Golgi. MVBs may fuse with lysosomes, and their cargoes will be degraded and recycled. Some MVBs fuse with the cell membrane and are transported into the extracellular milieu as exosomes $[33,34]$. Such endosomes are called MVBs because of their appearance, with many small vesicles ILVs, inside the larger body. The ILVs become exosomes if the MVB merges with the cell membrane, releasing the internal vesicles into the extracellular space. Several proteins are indispensable in the formation of exosomes, including endosomal sorting complex required for transport (ESCRT), ALG-2 interacting protein X (ALIX), soluble $\mathrm{N}$-ethylmaleimide-sensitive factor attachment protein receptors (SNAREs), tumor susceptibility 101 (TSG101), Rab GTPases, CD9, CD63, and CD81, some of which serve as markers of exosomes $[15,35,36]$. All these proteins play an integral role in the origin or biogenesis of $\mathrm{EVs}$, and the precise functions of these proteins deserve further in-depth investigation. Once secreted into the extracellular milieu or bloodstream, exosomes can be recognized by recipient cells and then dock the cellular membrane, resulting in alterations in the behavior and phenotype of recipient cells [37]. The fate of the exosomes and their effects on recipient cells may vary because of their different cargoes, as the manners of uptake and utilization are complex. Upon docking at the plasma membrane, exosomes can fuse with the cellular membrane and deliver cargoes into the cytoplasm. In this process, recipient cells can internalize exosomes in several possible ways, including phagocytosis, macropinocytosis, caveolae-dependent endocytosis, and clathrin-dependent endocytosis $[38,39]$. The different uptake pathways might rely on the types and physiologic state of recipient cells. For example, oncogenic KRAS expression can enhance exosome uptake efficacy by macropinocytosis in $\mathrm{PaCa}$ [40]. Cardiomyocytes can uptake circulating exosomal miRNAs via clathrin-mediated endocytosis, and human melanoma cells more readily rely on fusion 


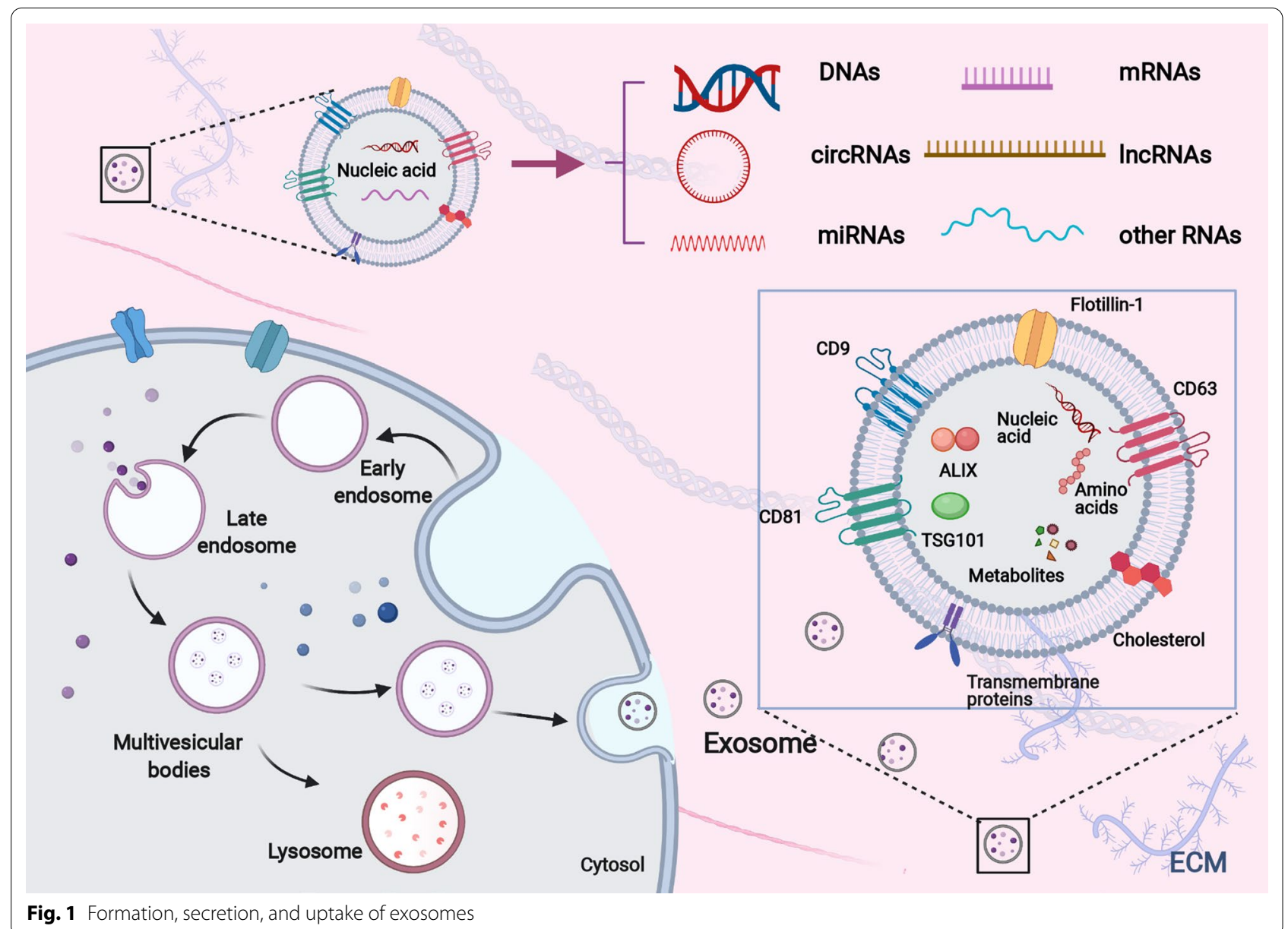

with the plasma membrane for exosome uptake [41, 42]. After internalization, exosomes can deliver functional cargoes as the endpoint. In many cases, those exosomes can be released de novo by recipient cells, or the contents of exosomes are secreted into the endoplasmic reticulum and/or cytoplasm after the disintegration of intracellular vesicles such as endosomes or MVBs [43]. The different fates may depend on specific ligand receptors on the surface of exosomes and acceptor cells, but the exact mechanisms await further investigation.

\section{Current methods and challenges of the purification of exosomes}

As critical mediators of intercellular crosstalk, exosomes exist in virtually all body fluids, and highly purified exosomes are indispensable for further structural and functional study [44]. However, the acquirement of high-quality exosomes is still challenging due to exosome heterogeneity in the source, size, and content [45]. The International Society for Extracellular Vesicles has suggested that differential ultracentrifugation (DC) is the most frequently used method, with several other methods, such as density gradient ultracentrifugation (DGC), ultrafiltration (UF), precipitation, size-exclusion chromatography (SEC), and immunoaffinity capture [46]. We introduce the principles, advantages, and disadvantages of each of these conventional methods in Table 1. Although these conventional methods are widely available, several problems exist, such as labor- and timeconsuming process, co-existence with impurities, and potential risk of exosomal damage. These disadvantages make it challenging to apply in clinical practice, especially for point-of-care testing (POCT). Recently, microfluidic techniques and aptamer-based magnetic techniques have been introduced as novel strategies of exosomal purification, which may provide compensation for the limitations of conventional methods [47, 48]. Microfluidic devices, including physical property-based methods, immunechips capture, and comprehensive separation, have been developed for exosome purification $[49,50]$. Compared with conventional methods, microfluidic techniques have apparent strengths, such as smaller sample volumes, faster assay times, lower reagent volumes, and higher portability. However, several problems are still 





to be overcome, such as a lack of standardized protocol, further improvement in purity, and additional reduction in cost. Aptamer-based magnetic techniques have been reported to achieve the rapid capture, adequate enrichment, and safe release of exosomes [51]. Therefore, this exosome purification method can potentially be applied to further investigations of exosomes and clinical translation of diagnosis and therapeutics. Nevertheless, there is neither sufficient evidence on the stability nor enough aptamer selection, which has limited the broad adaptability of their applications.

\section{Exosomal RNAs play pivotal roles in $\mathrm{PaCa}$ development and progression (Fig. 2)}

Exosomes are loaded with multiple cargoes, such as RNAs, DNAs, proteins, and lipids, and thus the delivery of exosomes plays pivotal roles in diverse physiological and pathophysiological processes [9]. Investigations into the correlation between exosomes and tumors have progressed rapidly, which has led to numerous significant discoveries in the development and progression of tumors, including proliferation, apoptosis, angiogenesis, migration, invasion, metastasis, immune escape, and drug resistance [20,52-56]. Among these, exosomal RNAs have been intensively studied due to their essential roles in regulating all aspects of tumor metabolism and function [57]. In PaCa, cancer cells can be influenced by exosomal RNAs secreted from neighboring cancer cells or other cells, such as pancreatic stellate cells (PSCs), tumor-associated macrophages (TAMs), and cancerassociated fibroblasts (CAFs) [58-60]. Exosomal RNA delivery ultimately modulates the various features of $\mathrm{PaCa}$, and many scholars have interpreted the role of exosomal RNAs in $\mathrm{PaCa}$ development and progression (Table 2).

\section{Proliferation and angiogenesis}

Proliferation and angiogenesis are crucial elements in the rapid growth and development of $\mathrm{PaCa}$, contributing to the severity of the disease. Recently, researchers have demonstrated that exosomal RNAs regulate the proliferation of $\mathrm{PaCa}$ by influencing the expression of multiple genes and activating different signaling pathways. For instance, tumor-derived exosomal miRNA-222 was reported to promote the proliferation and invasion of $\mathrm{PaCa}$ cells via increasing p27 phosphorylation by activating Akt signaling [61]. In another study, TAMderived exosomal miRNA-501-3p was found to increase tumorigenesis and metastasis through the transforming growth factor- $\beta$ receptor 3 (TGFBR3) -mediated

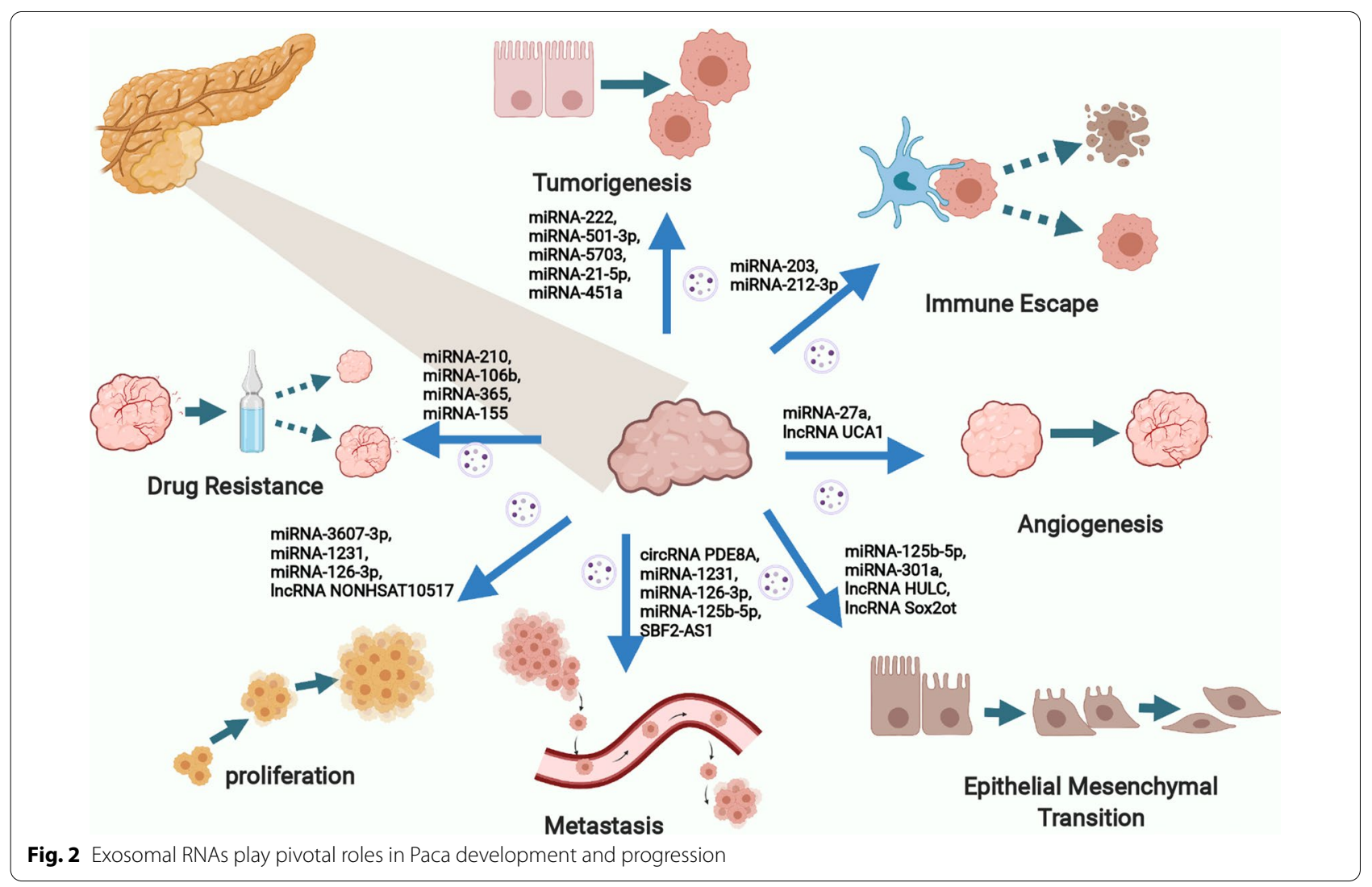


TGF- $\beta$ signaling pathway [62]. In addition, PSC-derived exosomal miRNA-5703 was found to promote $\mathrm{PaCa}$ proliferation by downregulating CKLF like MARVEL transmembrane domain-containing protein 4 (CMTM4) and activating the PI3K/Akt pathway [63]. Although the origins and targeted signaling pathways vary, exosomal RNAs appear to play multiple crucial roles in PaCa proliferation. In contrast, some exosomal RNAs have opposite effects, such as inducing apoptosis. In this regard, Sun et al. found that natural killer (NK) cell-derived exosomal miRNA-3607-3p inhibits PaCa proliferation, migration, and invasion by targeting IL-26 [64]. Additionally, exosomal miRNA-1231 and miRNA-126-3p, secreted by bone marrow mesenchymal stem cells (BM-MSCs), are implicated in inhibiting the proliferation, migration, and invasion of PaCa cells [65, 66]. Likewise, miRNA-126-3p promotes the apoptosis of $\mathrm{PaCa}$ cells by silencing of a disintegrin and a metalloproteinase 9 (ADAM9)[66]. In summary, exosomal RNAs are capable of both promoting and inhibiting carcinogenesis depending on their different mechanisms. As a unique link between proliferation and apoptosis, angiogenesis is deeply involved in tumor growth and metastatic dissemination [67]. Several exosomal RNAs have been identified to be associated with angiogenesis in $\mathrm{PaCa}$. Tumor-derived exosomal miRNA27 a was found to promote angiogenesis in $\mathrm{PaCa}$ via $\mathrm{B}$-cell translocation gene 2 (BTG2) [68]. Additionally, hypoxic tumor-derived exosomal IncRNA urothelial cancer-associated 1 (UCA1) was shown to promote angiogenesis via miRNA-96-5p/AMOTL2 (angiomotin-like 2) in $\mathrm{PaCa}$ [69]. Above all, these studies show how exosomal RNAs with different functions from diverse origins can affect tumor growth. However, we cannot attribute the poor prognosis only to the presence of highly proliferative cancer cells, as the prognosis is affected by multiple factors, including migration, invasion, metastasis, immune escape, and drug resistance.

\section{Migration, invasion, and metastasis}

$\mathrm{PaCa}$ is characterized by aggressive features including migration, invasion, and metastasis, which always cause early treatment failure [58]. With these features, cancer cells are able to move to adjacent and distant areas and even settle in secondary tissues and organs [70]. As mentioned above, several exosomal RNAs (including miRNA222, miRNA-501-3p, miRNA-5703, miRNA-3607-3p, miRNA-1231, miRNA-126-3p) have been found to promote or inhibit $\mathrm{PaCa}$ migration, invasion, and metastasis [61-66]. Additionally, CAF-secreted exosomal miRNA$10 \mathrm{a}-5 \mathrm{p}$ was found to promote migration and invasion in $\mathrm{PaCa}$ cells, while activating vitamin $\mathrm{D}$ receptor (VDR) signaling could inhibit these supportive effects on $\mathrm{PaCa}$ cells [71]. Similarly, CAF-derived exosomal miRNA-21,
miRNA-221, PSC-derived exosomal miRNA-21-5p, and miRNA-451a were reported to confer aggressive features in $\mathrm{PaCa}$ cells $[72,73]$. In the context of inhibitory effects, NK cell-derived exosomal miRNA-3607-3p was reported to inhibit the migration and invasion of $\mathrm{PaCa}$ cells by directly targeting IL-26 [64]. In addition, BM-MSCsderived exosomal miRNA-1231 and miRNA-126-3p were also indicated to act inhibitory roles of the migration and invasion of $\mathrm{PaCa}$ cells $[65,66]$. Interestingly, exosomal lncRNAs and circRNAs seem to be more active in migration, invasion, and metastasis than that in proliferation in PaCa. Tumor-derived exosomal lncRNA SBF2 antisense RNA 1 (SBF2-AS1), highly upregulated in liver cancer (HULC), NONHSAT105177, SOX2 overlapping transcript (Sox2ot), circRNA phosphodiesterase 8A (PDE8A), and isoleucyl-tRNA synthetase (IARS) have already been reported to affect the migration, invasion, and metastasis of PaCa cells [74-79]. Naturally, exosomal RNAs can also act as suppressive factors, as mentioned above. Thus, exosomal RNAs can act as major regulators of migration, invasion, and metastasis, promoting (or inhibiting) the progression of $\mathrm{PaCa}$. Moreover, epithelial-mesenchymal transition (EMT) is a special biological process involved in the migration, invasion, and metastasis [80]. In this process, in which epithelial cells become mesenchymal cells via loss of cell polarity and gain of molecular alterations [81].EMT is characterized by the loss of epithelial E-cadherin and the acquisition of mesenchymal markers such as $\mathrm{N}$-cadherin, fibronectin, and vimentin [82-84]. Recently, several exosomal RNAs have been reported to promote EMT in $\mathrm{PaCa}$ [29]. For instance, tumor-derived exosomal miRNA-125b-5p was found to be upregulated in highly invasive $\mathrm{PaCa}$ cells, facilitating migration, invasion, and EMT via the activation of MEK2/ERK2 signaling [85]. In addition, exosomal miRNA-301a, lncRNA HULC, and NONHSAT105177 were also reported to contribute to EMT in $\mathrm{PaCa}[75,76,86]$. Above all, we believe that these findings will be of great value if these factors are applied as targets for therapeutic intervention.

\section{Immune escape}

The immune system is a complicated network of diverse cells and biomolecules that prospect the body against infection, cancer, and other harmful circumstances. Gene mutations and the abnormal proliferation of cancer cells can produce different types of antigens; these antigens allow the detection and elimination of cancer cells by a large variety of immune response factors, preventing potential malignant transformation. Exosomes have been previously well studied in the context of the immune response, and scholars have proposed many mechanisms that explain how cancer cells promote immune escape and cancer development [18, 87, 88]. Several 
studies have pointed out that tumor-derived exosomes realized immune escape by inhibiting the activation of immune cells, causing a functional loss in immune responses[89-92]. Dendritic cells (DCs) serve as the most critical antigen-presenting cells (APCs) of the human immune system, and they function by promoting the expression of Toll-like receptors (TLRs) and generating multiple interleukins (ILs). Among TLRs, TLR4 exhibits a powerful antitumor effect [93]. In PaCa, tumor-derived exosomal miRNA-203 was reported to downregulate TLR4 and downstream tumor necrosis factor $\alpha$ (TNF$\alpha)$ and IL-12 in DCs, which may help PaCa cells achieve immune escape [94]. In another study, tumor-derived exosomal miRNA-212-3p was found to inhibit the expression of RFX-associated protein (RFXAP), which decreased the expression of major histocompatibility complex class II (MHC II) and mediated the immune tolerance of DCs [95]. These findings infer that exosomal RNAs can harbor functional immune activity, allowing $\mathrm{PaCa}$ cells to escape immune surveillance. However, relative to that in other research areas, our knowledge about how exosomes help cancers cells escape the immune system in PaCa is still limited, and additional work is needed to address this issue. Deeper insight into the relationship between exosomes and immune escape is likely to be beneficial for the identification of potential biomarkers and the development of therapeutics.

\section{Drug resistance}

Systemic chemotherapy combinations, including gemcitabine (GEM) plus other drugs, are still the cornerstone of treatment for advanced $\mathrm{PaCa}$ [3], while drug resistance remains a severe challenge in the context of antitumor therapy. To our knowledge, cancer cells can develop drug resistance via enhanced DNA repair, altered membrane transport, defective apoptotic pathways, etc. [96]. The effect of exosomes in the process cannot be ignored. In normal cells, exosomes are responsible for the transport of many cargoes from one cell to another. Studies have demonstrated that, once drug-resistant cancer cells develop, exosomes loaded with so-called "anti-chemotherapy" information can confer drug resistance to sensitive cells $[97,98]$. In PaCa, several exosomal RNAs have been discovered to play essential roles in drug resistance. For example, exosomes derived from GEM-resistant $\mathrm{PaCa}$ cells were found to enhance the drug resistance of other cancer cells by delivering miRNA-210 [99]. Another study indicated that CAF-derived exosomal miRNA-106b promoted PaCa GEM-resistance via tumor protein 53-induced nuclear protein 1 (TP53INP1) [100]. Likewise, the delivery of miRNA-365 in TAM-derived exosomes was shown to potentiate the GEM-response in $\mathrm{PaCa}[101]$. Notably, with a series of successive validation studies, tumor-derived exosomal miRNA-155 was proven to be a vital related to GEM-resistance [102, 103]. These studies highlight the relationship between exosomal RNAs and GEM-resistance that exosomal RNAs can accelerate the acquisition of GEM-resistance and mitigate the cell-killing effect. In addition to newer therapeutic strategies, chemotherapy and radiotherapy still have considerable prospects for $\mathrm{PaCa}$ [104]. Similar to their regulatory roles in drug resistance, exosomal RNAs can also impact the outcome of radiotherapy. It has been reported that dying post-radiotherapy $\mathrm{PaCa}$ cells can deliver exosomal miRNA-194-5p to potentiate cell repopulation survival by modulating the expression of E2F transcription factor 3 (E2F3) [105]. In another study, exosomal hsa_circ_0002130 was considered to modulate cancer cell repopulation after radiation [106]. Overall, exosomal RNAs are related to the emergence of both drug resistance and radiotherapy resistance, and we believe that novel treatments targeting exosome-specific therapeutic resistance markers will be developed soon.

\section{Exosomal RNAs as potential biomarkers for $\mathrm{PaCa}$}

With very few specific symptoms in the early period, $\mathrm{PaCa}$ is often diagnosed in an advanced stage, which leads to a high fatality rate [107]. Traditional imaging examinations, such as ultrasound, CT, and MRI, are widely used in the clinical evaluation of PaCa. Although CA-199 is the only FDA-approved biomarker of $\mathrm{PaCa}$, its accuracy is far from satisfactory due to the poor sensitivity at an early stage and the relatively low specificity overall [108-110]. Therefore, a more precise method is urgently needed for non-invasive diagnosis. As mentioned earlier, exosomes are enriched with biological cargoes, so they have gained interest as potential biomarkers for the early diagnosis of multiple malignancies [111]. Among these, exosomal RNAs are emerging as novel biomarkers for $\mathrm{PaCa}$ (Table 3). Accumulated evidence has revealed that exosomal RNAs can be more valuable in diagnosis than peripheral blood-free RNA as they have several advantages: exosomes can prevent RNAs from being degraded via RNases; exosomal RNAs are more closely associated with those of the original cells; and there is a higher concentration of RNAs in exosomes, which can yield more information [112-114].

Among all exosomal cargoes, exosomal miRNAs are currently regarded as the most promising biomarkers because of their abundance and easy accessibility, indicating that they can be used as potential diagnostic tools; in addition, they are closely related to the outcome and recurrence of $\mathrm{PaCa}$ [115]. For example, several studies indicated that elevated exosomal miRNA-21 levels can not only discriminate $\mathrm{PaCa}$ patients from healthy individuals and patients with other pancreatic diseases (e.g., 
Table 2 Exosomal RNAs involved in the development and progression in $\mathrm{PaCa}$

\begin{tabular}{|c|c|c|c|c|c|}
\hline RNA Type & Molecules & Origin & Effects & Targets & Refs. \\
\hline \multirow[t]{21}{*}{ miRNA } & miRNA-222 & TDEs & $\begin{array}{l}\text { Proliferation } \uparrow \\
\text { Invasion } \uparrow\end{array}$ & p27/Akt & {$[61]$} \\
\hline & miRNA-501-3p & TAMs & $\begin{array}{l}\text { Tumorigenesis } \uparrow \\
\text { Metastasis } \uparrow\end{array}$ & TGFBR3/TGF- $\beta$ & {$[62]$} \\
\hline & miRNA-5703 & PSCS & Proliferation $\uparrow$ & CMTM4/PI3K/Akt & [63] \\
\hline & miRNA-3607-3p & NK cells & $\begin{array}{l}\text { Proliferation } \downarrow \\
\text { Migration } \downarrow \\
\text { Invasion } \downarrow\end{array}$ & IL-26 & {$[64]$} \\
\hline & miRNA-1231 & BM-MSCs & $\begin{array}{l}\text { Proliferation } \downarrow \\
\text { Migration } \downarrow \\
\text { Invasion } \downarrow\end{array}$ & Not mentioned & {$[65]$} \\
\hline & miRNA-126-3p & BM-MSCs & $\begin{array}{l}\text { Proliferation } \downarrow \\
\text { Migration } \downarrow \\
\text { Invasion } \downarrow\end{array}$ & ADAM9 & {$[66]$} \\
\hline & miRNA-27a & TDES & Angiogenesis $\uparrow$ & BTG2 & {$[68]$} \\
\hline & miRNA-10a-5p & CAFs & $\begin{array}{l}\text { Migration } \uparrow \\
\text { Invasion } \uparrow\end{array}$ & VDR & {$[71]$} \\
\hline & miRNA-21 & CAFs & $\begin{array}{l}\text { Migration } \uparrow \\
\text { Invasion } \uparrow\end{array}$ & Not mentioned & {$[72]$} \\
\hline & miRNA-221 & CAFs & $\begin{array}{l}\text { Migration } \uparrow \\
\text { Invasion } \uparrow\end{array}$ & NF-k B/KRAS & {$[72]$} \\
\hline & miRNA-21-5p & PSCS & $\begin{array}{l}\text { Proliferation } \uparrow \\
\text { Migration } \uparrow\end{array}$ & Not mentioned & {$[73]$} \\
\hline & miRNA-451a & PSCS & $\begin{array}{l}\text { Proliferation } \uparrow \\
\text { Migration } \uparrow\end{array}$ & Not mentioned & {$[73]$} \\
\hline & miRNA-125b-5p & TDEs & $\begin{array}{l}\text { Migration } \uparrow \\
\text { Invasion } \uparrow \\
\text { EMT } \uparrow\end{array}$ & MEK2/ERK2 & {$[85]$} \\
\hline & miRNA-301a & TDEs & $\begin{array}{l}\text { Migration } \uparrow \\
\text { Invasion } \uparrow \\
\text { EMT } \uparrow\end{array}$ & PTEN/PI3KY & {$[86]$} \\
\hline & miRNA-203 & TDEs & Immune Escape $\uparrow$ & TNF-a/IL-12/TLR4 & [94] \\
\hline & miRNA-212-3p & TDEs & Immune Escape $\uparrow$ & RFXAP/MHC II & {$[95]$} \\
\hline & miRNA-210 & TDEs & GEM-resistance $\uparrow$ & mTOR & [99] \\
\hline & miRNA-106b & CAFs & GEM-resistance $\uparrow$ & TP53INP1 & [100] \\
\hline & miRNA-365 & TAMs & GEM-resistance $\uparrow$ & NTP/CDA & [101] \\
\hline & miRNA-155 & TDEs & GEM-resistance $\uparrow$ & SOD/CAT/DCK & [103] \\
\hline & miRNA-194-5p & TDEs & Radiotherapy-resistance $\uparrow$ & E2F3 & [105] \\
\hline \multirow[t]{5}{*}{ IncRNA } & UCA1 & TDEs & Angiogenesis $\uparrow$ & miRNA-96-5p/AMOTL2 & {$[69]$} \\
\hline & SBF2-AS1 & TAMs & $\begin{array}{l}\text { Migration } \uparrow \\
\text { Invasion } \uparrow \\
\text { Metastasis } \uparrow\end{array}$ & miRNA-122-5p/XIAP & {$[74]$} \\
\hline & HULC & TAMs & $\begin{array}{l}\text { EMT } \uparrow \\
\text { Invasion } \uparrow \\
\text { Migration } \uparrow\end{array}$ & Not mentioned & {$[75]$} \\
\hline & NONHSAT105177 & TDEs & $\begin{array}{l}\text { Proliferation } \downarrow \\
\text { Migration } \downarrow \\
\text { EMT } \downarrow\end{array}$ & Clusterin & {$[76]$} \\
\hline & Sox2ot & TDEs & $\begin{array}{l}\text { Invasion } \uparrow \\
\text { Metastasis } \uparrow \\
\text { EMT } \uparrow\end{array}$ & miRNA-200 family/ Sox2 & {$[77]$} \\
\hline \multirow[t]{3}{*}{ circRNA } & PDE8A & TDEs & Invasion $\uparrow$ & miRNA-338/MACC1/MET & {$[78]$} \\
\hline & IARS & TDEs & Metastasis $\uparrow$ & HUVECS & {$[79]$} \\
\hline & hsa_circ_0002130 & TDEs & Radiotherapy-resistance $\uparrow$ & Not mentioned & {$[106]$} \\
\hline
\end{tabular}


chronic pancreatitis and intraductal papillary mucinous neoplasm) but can also help make an early diagnosis and evaluate tumor stage [116-119]. Moreover, other exosomal miRNAs, including miRNA-210, miRNA-10b, miRNA-451a and miRNA-1246, can be applied for the accurate and early diagnosis of $\mathrm{PaCa}[116,117,120,121]$. Notably, some exosomal miRNAs may be correlated with tumor recurrence or may even be independent prognostic factors for PaCa. For instance, high-level expression of exosomal miRNA-451a was found to be associated with an increased risk of cancer recurrence and poorer prognosis in $\mathrm{PaCa}$ [122]. Similarly, another study illustrated that a higher exosomal miRNA-222 level was one of the independent risk factors for PaCa patients, which could reflect an enlarged tumor size and a high TNM stage [61]. Apart from peripheral blood, exosomes collected from other bodily fluids may also contribute to $\mathrm{PaCa}$ diagnosis and prognosis prediction [123]. First, portal vein blood assessment of exosomal miRNA-4525, miRNA-451a, and miRNA-21 was confirmed to outperform peripheral blood assessment evaluating both disease-free survival and overall survival in PaCa patients [124]. Next, pancreatic juice exosomal miRNA-21 and miRNA-155 levels were shown to discriminate $\mathrm{PaCa}$ patients from chronic pancreatitis patients with better performance than blood-free exosomal miRNA and CA-199 levels [125]. In addition, salivary miRNA-1246 and miRNA-4644 were found to be promising biomarkers for $\mathrm{PaCa}$ [126]. Naturally, some researchers preferred combinations of multiple exosomal miRNAs or of exosomal miRNAs and other biomarkers to achieve better diagnostic yield in $\mathrm{PaCa}$ evaluation [127-129]. For example, a 3D microfluidic chip was designed to assess multiple exosomal biomarkers including surface proteins (CD81, EphA2, and CA-199) and exosomal miRNAs (miRNA-451a, miRNA21 , and miRNA-10b), and the accuracy of diagnosis and stage monitoring reached up to approximately $100 \%$ [130]. In another study, a six-miRNA panel, including let7b-5p, miRNA-192-5p, miRNA-19a-3p, miRNA-19b-3p, miRNA-223-3p, and miRNA-25-3p, was introduced to facilitate early and noninvasive diagnosis of $\mathrm{PaCa}$ early from both serum and exosomal specimens [131]. In addition to improving diagnostic yield, researchers have introduced many new techniques to better detect exosomal RNAs [132-134]. Typically, Pang et al. invented a biosensor for one-step detection of exosomal miRNAs, which could be of great value for applying point-of-care cancer diagnosis in terms of accuracy and convenience [135]. Overall, we believe that exosomal miRNAs can certainly be applied to improve the diagnosis and prognosis of $\mathrm{PaCa}$.

Although existing studies on exosomal lncRNAs, circRNAs, and mRNAs are limited compared to those on exosomal miRNAs, these molecules can also facilitate $\mathrm{PaCa}$ diagnosis. Some scholars have suggested that many exosomal lncRNAs serve as tumor biomarkers for $\mathrm{PaCa}$. For example, high expression of Sox2ot in plasma exosomes was shown to predict late TNM stage and poor survival in $\mathrm{PaCa}$ patients [77]. Additionally, exosomal lncRNA HULC, colorectal neoplasia differentially expressed (CRNDE), and metastasis-associated lung adenocarcinoma transcript 1 (MALAT-1) were proven to have potential value in discriminating $\mathrm{PaCa}$ from other pancreatic diseases $[75,136]$. Exosomal circRNAs are another kind of endogenous non-coding RNAs, and information on their importance in tumors and other diseases is emerging [137, 138]. In PaCa, both exosomal circRNA PDE8A and IARS are correlated with progression and prognosis $[78,79]$. Studies have proposed that exosomal circRNAs will soon serve as novel biomarkers for PaCa. Moreover, exosomal mRNAs have recently been discovered as potential diagnostic biomarkers. For example, exosomal mRNA Wiskott-Aldrich syndrome protein Verprolin-homologous protein 2 (WASF2) provided excellent accuracy for distinguishing $\mathrm{PaCa}$ patients from healthy individuals, and distinguishing $\mathrm{PaCa}$ patients between stage 0/I/IIA and stage IIB/III/IV [139]. Another exosomal mRNA, glypican-1 (GPC1), provided excellent diagnostic performance in differentiating $\mathrm{PaCa}$ patients from patients with other pancreatic diseases and from healthy individuals, approaching $100 \%$ sensitivity and specificity [140].

Above all, exosomal RNAs are implied to be potential diagnostic and prognostic biomarkers for $\mathrm{PaCa}$, as summarized in Table 3. With the emphasis on their potential value as $\mathrm{PaCa}$ biomarkers, we still need more experiments to verify their significance in the diagnosis and prognosis evaluation of $\mathrm{PaCa}$. Ultimately, there remains an endless challenge to identify additional sensitive and specific exosomal biomarkers with the growth of our knowledge in the field of exosomes. Even though substantial advancements have been achieved, there is a long path ahead before discovering a perfect $\mathrm{PaCa}$ biomarker.

\section{The therapeutic value of exosomes in the treatment of $\mathrm{PaCa}$}

$\mathrm{PaCa}$ is one of the deadliest malignant tumors, and thus scientists have devoted significant efforts to seek better-targeted therapies [141, 142]. With the function of drug-payload delivery, exosomes have been increasingly explored as therapeutic agents [14, 143] (Fig. 3). Among all the drug cargoes loaded into exosomes, nucleic acids, especially miRNAs, small interfering RNA (siRNA), and hairpin RNA (shRNA), are the most favorite constructs [144]. Generally, those cargoes can be loaded into exosomes either before or after purification. In 


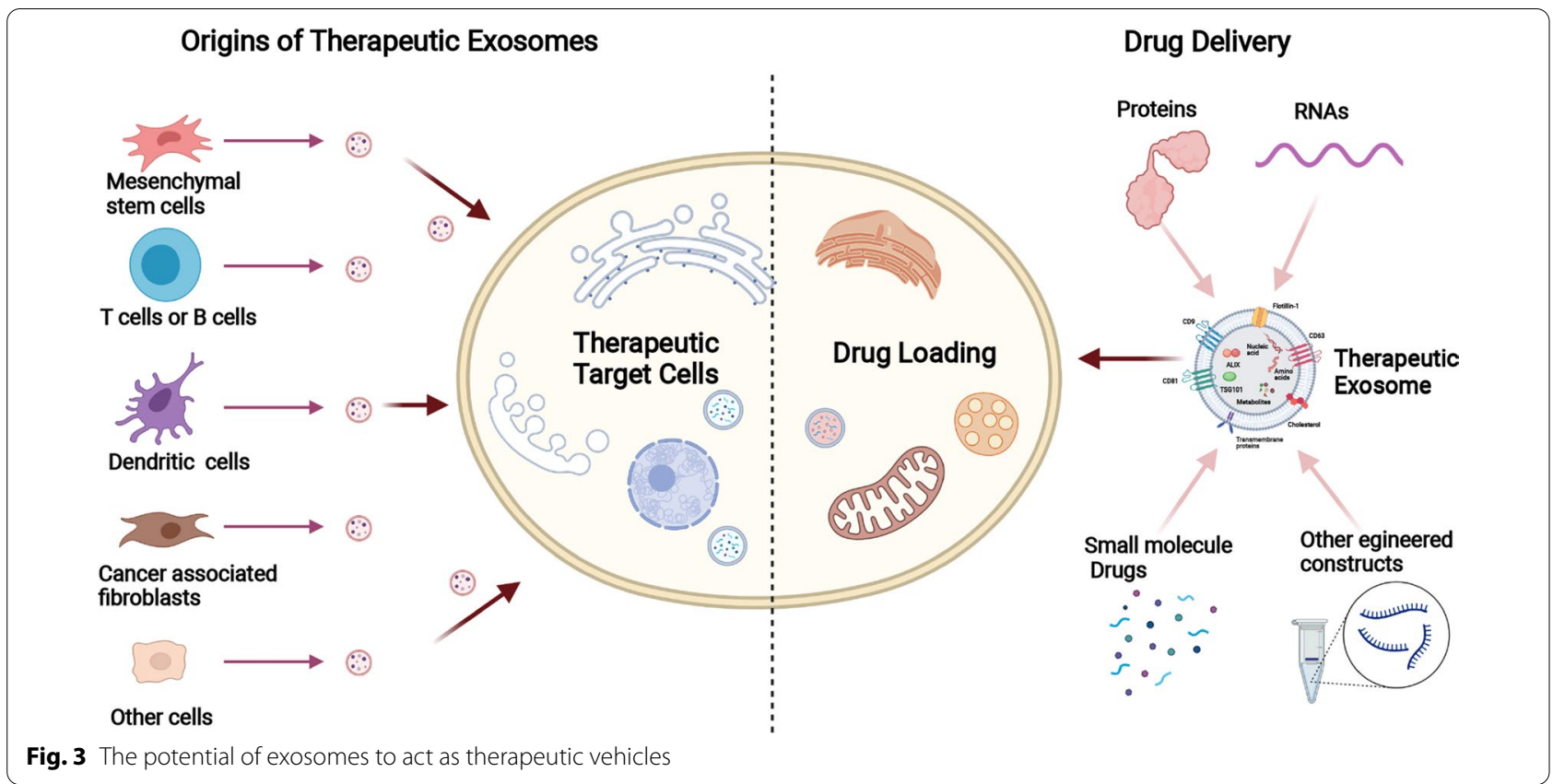

most cases, those cargoes can be loaded via incubation, transfection-based methods, or ultraviolet irradiation before purification [145-147]; whereas after purification, they can be loaded into exosomes by either physical methods (such as electroporation, plain incubation, and sonication), or chemical procedures (such as transfection kit, and mix with organic solvent) [148-152]. In contrast to previous drug carriers (e.g., liposomes),

Table 3 Exosomal RNAs as biomarkers for Paca

\begin{tabular}{|c|c|c|c|c|}
\hline RNA Type & Molecules & Origin & Potential functions & Refs. \\
\hline \multirow[t]{13}{*}{ miRNA } & miRNA-21 & Peripheral blood & Early diagnosis/tumor stage/survival evaluation & {$[116-119]$} \\
\hline & miRNA-210 & Peripheral blood & Early diagnosis/tumor stage & {$[116]$} \\
\hline & miRNA-10b & Peripheral blood & Early diagnosis & {$[117,120]$} \\
\hline & miRNA-1246 & Peripheral blood & Early diagnosis & {$[121]$} \\
\hline & miRNA-451a & Peripheral blood & Tumor stage/survival evaluation & {$[122]$} \\
\hline & miRNA-222 & Peripheral blood & Tumor stage/survival evaluation & {$[61]$} \\
\hline & miRNA-4525 & Portal vein blood & Recurrence prediction/survival evaluation & {$[124]$} \\
\hline & miRNA-451a & Portal vein blood & Recurrence prediction/survival evaluation & {$[124]$} \\
\hline & miRNA-21 & Portal vein blood & Recurrence prediction/survival evaluation & {$[124]$} \\
\hline & miRNA-21 & Pancreatic juice & Early diagnosis & {$[125]$} \\
\hline & miRNA-155 & Pancreatic juice & Early diagnosis & {$[125]$} \\
\hline & miRNA-1246 & Salivary & Early diagnosis & {$[126]$} \\
\hline & miRNA-4644 & Salivary & Early diagnosis & {$[126]$} \\
\hline \multirow[t]{4}{*}{ IncRNA } & Sox2ot & Peripheral blood & Tumor stage/survival evaluation & {$[77]$} \\
\hline & HULC & Peripheral blood & Early diagnosis & {$[75]$} \\
\hline & CRNDE & Peripheral blood & Early diagnosis & {$[136]$} \\
\hline & MALAT-1 & Peripheral blood & Early diagnosis & {$[136]$} \\
\hline \multirow[t]{2}{*}{ circRNA } & PDE8A & Peripheral blood & Tumor stage/survival evaluation & {$[78]$} \\
\hline & IARS & Peripheral blood & Tumor stage/survival evaluation & {$[79]$} \\
\hline \multirow[t]{2}{*}{ mRNA } & WASF2 & Peripheral blood & Early diagnosis/tumor stage/ & {$[139]$} \\
\hline & GPC1 & Peripheral blood & Early diagnosis/tumor stage/ & {$[140]$} \\
\hline
\end{tabular}


injected exosomes can be taken up by other cells more effectively and confer bioactive cargoes with less immune interference [23, 153, 154]. In addition, the heterogeneity of surface molecules on exosomes is more suitable for receptor-targeted features, which realize exosometargeted therapy [155]. Hence, the therapeutic utilization of exosomes as nanocarriers has excellent potential. Currently, researchers are committed to engineering exosomes for the encapsulation of therapeutic ingredients. For example, Zhou et al. loaded purified exosomes with paclitaxel and gemcitabine monophosphate, and these exosomes showed extraordinary penetrating abilities and yielded excellent targeted chemotherapy efficacy [156]. It is well known that the KRAS gene is closely associated with cell proliferation, survival, and differentiation, so multiple studies have been conducted on the KRAS gene. Kamerkar et al. engineered exosomes to deliver siRNA or shRNA targeting KRAS in PaCa cells, which successfully inhibited tumor growth in mouse models and improved overall survival [40]. Likewise, Mendt et al. engineered exosomes with siRNA to target KRAS G12D, which increased the survival of several mouse models with Paca [157]. Moreover, the MD Anderson Cancer Center is leading a phase I clinical trial of MSCderived exosomes with KRAS G12D siRNA to treat patients with KRAS G12D mutation-associated PaCa (NCT03608631).

Regardless of the exciting progress and these pioneering developments, using engineered exosomes as vehicles in the clinical treatment of $\mathrm{PaCa}$ still presents several challenges. First, it is not easy to ensure the homogeneity of the treatment effect of different exosomes, as the alignments probably having varying degrees of the same therapeutic implication. Subsequently, the present isolation techniques of exosomes are relatively suboptimal for the requirement of immunotherapy. Overall, increasing studies and achievements in exosome extraction techniques will facilitate the application of exosomes in the clinical treatment of $\mathrm{PaCa}$.

\section{Conclusions and perspective}

Above all, exosomes are special vesicles that mediate diverse biological functions. In this review, we highlighted the vital role of exosomal RNAs in PaCa. These discoveries may spark more studies to elucidate the pathogenesis and mechanism of $\mathrm{PaCa}$, offering a new direction and important guidance for the diagnosis and treatment of PaCa. Nevertheless, the question remains whether observed biological activities, including the phenotypic and molecular alterations, can still persist under physiological conditions, which merits further validation.

Characterized by high specificity and minimally invasive nature, exosomal RNAs exhibit outstanding value as potential biomarkers for PaCa. However, large-scale studies are warranted to validate the clinical application of exosomal RNAs. To gain a greater value of the management of $\mathrm{PaCa}$, exosomal RNAs may need to be more intensively studied to develop new utilities monitoring the outcome of therapy. In addition to simple prediction of recurrence and prognosis, if we can adjudicate a certain recurrence, judge the existence of metastasis, observe the therapeutic efficacy, or even determine the length of survival by just testing a specific exosomal RNA (or a set of exosomal RNAs), it will be of great convenience for both the patients and doctors. In terms of therapeutic applications of exosomes (represented by engineered exosomes), several major challenges remain for investigators, such as the evaluation of adverse effects and the identification of tolerated doses. In addition, it is vital to discover more active pharmaceutical ingredients, and identify their specific mechanisms, ensuring the homogeneity of in the treatment effect. Finally, back to the basics, the acquirement of high-quality exosomes is still challenging, and several obstacles are still formidable, including standardization, improvements in throughput and purity, cost reduction, and increased exosome recovery. These problems, when resolved, will bring the bottomup promotion to the application of exosomes to every degree.

\section{Abbreviations}

PaCa: Pancreatic cancer; ncRNAs: Non-coding RNAs; EVs: Extracellular vesicles; TME: Tumor microenvironment; TDEs: Tumor cell-derived exosomes; miRNAs: MicroRNAs; IncRNAs: Long non-coding RNAs; circRNAs: Circular RNAs; MVBs: Multivesicular bodies; ILVs: Intraluminal vesicles; ESCRT: Endosomal sorting complex required for transport; ALIX: ALG-2 interacting protein X; SNAREs: Soluble $\mathrm{N}$-ethylmaleimide-sensitive factor attachment protein receptors; TSG101: Tumor susceptibility 101; DC: Differential ultracentrifugation DGC: density gradient ultracentrifugation; UF: Ultrafiltration; SEC: Size-exclusion chromatography; POCT: Point-of-care testing; PSCs: Pancreatic stellate cells;

TAMs: Tumor-associated macrophages; CAFs: Cancer-associated fibroblasts; PPP2R2A: Protein phosphatase 2 regulatory subunit Balpha; Akt: Protein kinase $B$; TGFBR3: Transforming growth factor $\beta$ $\beta$ receptor 3 ; PI3K: Phosphoinositide 3-kinase; CMTM4: CKLF like MARVEL transmembrane domain-containing protein 4; NK cell: Natural killer cell; BM-MSCs: Bone marrow mesenchymal stem cells; ADAM9: A disintegrin and a metalloproteinase 9; BTG2: B-cell translocation gene 2; UCA1: Urothelial cancer-associated 1; AMOTL2: Angiomotin-like 2; VDR: Vitamin D receptor; SBF2-AS1: SBF2 antisense RNA 1; HULC: Highly upregulated in liver cancer; Sox2ot: SOX2 overlapping transcript; PDE8A: Phosphodiesterase 8A; IARS: Isoleucyl-tRNA synthetizes; EMT: Epithelial-mesenchymal transition; MEK2: Mitogen-activated protein kinase kinase 2; ERK2:

Extracellular signal-regulated kinase 2 PTEN: Phosphatase and tensin homolog; MACC: Metastasis-associated in colon cancer; MET: MET proto-oncogene, receptor tyrosine kinase; HUVECs: Human umbilical vein endothelial cells; DCs: Dendritic cells; APCs: Antigen-presenting cells; TLRs: Toll-like receptors; ILs: Interleukins TNF: Tumor necrosis factor; RFXAP: RFX-associated protein; MHC II: Major histocompatibility complex class II; GEM: Gemcitabine; mTOR: Mammalian target of rapamycin; TP53INP1: Tumor protein 53-induced nuclear protein 1; NTP: Nucleoside triphosphate; CDA: Cytidine deaminase; SOD: Superoxide dismutase 2; CAT: Catalase; DCK: Deoxycytidine kinase; E2F3: E2F transcription factor 3; CA-199: Carbohydrate antigen 199 XIAP: X-linked inhibitor of apoptosis protein; EphA2: Ephrin type-A receptor 2; IPMN: Intraductal papillary 
mucinous neoplasm; CP: Chronic pancreatitis; CRNDE: Colorectal neoplasia differentially expressed; MALAT-1: Metastasis-associated lung adenocarcinoma transcript 1; WASF2: Wiskott-Aldrich Syndrome Protein Family Member 2; GPC1: Glypican-1; siRNA: Small interfering RNA; shRNA: Small hairpin RNA.

\section{Acknowledgements}

Many important contributions could not be cited due to space constraints, and we apologize to our colleagues for any relevant exclusion. The figures in this manuscript were created with BioRender.com

\section{Authors' contributions}

ZZ and GZ conceived of the presented idea. ZZ wrote the manuscript with support from GZ, SY, and SZ (Shengtao Zhu). SZ (Shutian Zhang) and PL supervised the project. All authors read and approved the final manuscript.

\section{Funding}

This work was supported by National Natural Science Foundation of China (82070575), and Beijing Municipal Natural Science Foundation (J180010).

\section{Availability of data and materials}

No new data were created or analyzed in this study. Data sharing is not applicable to this article.

\section{Declarations}

\section{Ethics approval and consent to participate:}

Not applicable.

\section{Consent for publication}

Not applicable.

\section{Competing interests}

The authors declare no conflict of interest.

\section{Received: 26 April 2021 Accepted: 27 June 2021}

Published online: 09 July 2021

\section{References}

1. Sung H, Ferlay J, Siegel RL, Laversanne M, Soerjomataram I, Jemal A, Bray F. Global cancer statistics 2020: GLOBOCAN estimates of incidence and mortality worldwide for 36 cancers in 185 countries. CA Cancer J Clin. 2021;71(3):209-49.

2. Viale PH. The American Cancer Society's facts \& figures: 2020 edition. J Adv Pract Oncol. 2020;11(2):135-6.

3. Mizrahi JD, Surana R, Valle JW, Shroff RT. Pancreatic cancer. Lancet. 2020;395(10242):2008-20.

4. Henrikson NB, Aiello Bowles EJ, Blasi PR, Morrison CC, Nguyen M, Pillarisetty VG, Lin JS. Screening for pancreatic cancer: updated evidence report and systematic review for the US Preventive Services Task Force. JAMA. 2019;322(5):445-54.

5. Force USPST, Owens DK, Davidson KW, Krist AH, Barry MJ, Cabana M, Caughey AB, Curry SJ, Doubeni CA, Epling JW Jr, et al. Screening for pancreatic cancer: US Preventive Services Task Force reaffirmation recommendation statement. JAMA. 2019;322(5):438-44.

6. Kuehn BM. Looking to long-term survivors for improved pancreatic cancer treatment. JAMA. 2020;324(22):2242-4.

7. Sohal DPS, Kennedy EB, Cinar P, Conroy T, Copur MS, Crane CH, GarridoLaguna I, Lau MW, Johnson T, Krishnamurthi S, et al. Metastatic pancreatic cancer: ASCO guideline update. J Clin Oncol. 2020;38:3217-30.

8. Trams EG, Lauter CJ, Salem N Jr, Heine U. Exfoliation of membrane ecto-enzymes in the form of micro-vesicles. Biochim Biophys Acta. 1981;645(1):63-70.

9. Pegtel DM, Gould SJ. Exosomes. Annu Rev Biochem. 2019;88:487-514.

10. Lasda E, Parker R. Circular RNAs co-precipitate with extracellular vesicles: a possible mechanism for circRNA clearance. PLOS ONE. 2016;11(2):e0148407.

11. van Balkom BW, Eisele AS, Pegtel DM, Bervoets S, Verhaar MC. Quantitative and qualitative analysis of small RNAs in human endothelial cells and exosomes provides insights into localized RNA processing, degradation and sorting. J Extracell Vesicles. 2015;4:26760.

12. Pathan M, Fonseka P, Chitti SV, Kang T, Sanwlani R, Van Deun J, Hendrix A, Mathivanan S. Vesiclepedia 2019: a compendium of RNA, proteins, lipids and metabolites in extracellular vesicles. Nucleic Acids Res. 2019:47(D1):D516-9.

13. Keerthikumar S, Chisanga D, Ariyaratne D, Al Saffar H, Anand S, Zhao K, Samuel M, Pathan M, Jois M, Chilamkurti N, et al. ExoCarta: a web-based compendium of exosomal Cargo. J Mol Biol. 2016;428(4):688-92.

14. Kalluri R, LeBleu VS. The biology, function, and biomedical applications of exosomes. Science. 2020;367(6478):eaau6977.

15. Mathieu M, Martin-Jaular L, Lavieu G, Thery C. Specificities of secretion and uptake of exosomes and other extracellular vesicles for cell-to-cell communication. Nat Cell Biol. 2019;21(1):9-17.

16. Rajagopal C, Harikumar KB. The origin and functions of exosomes in cancer. Front Oncol. 2018;8:66

17. Zhang Y, Hu YW, Zheng L, Wang Q. Characteristics and roles of exosomes in cardiovascular disease. DNA Cell Biol. 2017;36(3):202-11.

18. Kurywchak P, Tavormina J, Kalluri R. The emerging roles of exosomes in the modulation of immune responses in cancer. Genome Med. 2018;10(1):23

19. Foster BP, Balassa T, Benen TD, Dominovic M, Elmadjian GK, Florova V, Fransolet MD, Kestlerova A, Kmiecik G, Kostadinova IA, et al. Extracellular vesicles in blood, milk and body fluids of the female and male urogenital tract and with special regard to reproduction. Crit Rev Clin Lab Sci. 2016;53(6):379-95.

20. Stefanius K, Servage K, de Souza Santos M, Gray HF, Toombs JE, Chimalapati S, Kim MS, Malladi VS, Brekken R, Orth K. Human pancreatic cancer cell exosomes, but not human normal cell exosomes, act as an initiator in cell transformation. Elife. 2019;8:e40226.

21. Zhang H, Deng T, Liu R, Bai M, Zhou L, Wang X, Li S, Wang X, Yang H, Li $J$, et al. Exosome-delivered EGFR regulates liver microenvironment to promote gastric cancer liver metastasis. Nat Commun. 2017:8:15016.

22. Costa-Silva B, Aiello NM, Ocean AJ, Singh S, Zhang H, Thakur BK, Becker A, Hoshino A, Mark MT, Molina $\mathrm{H}$, et al. Pancreatic cancer exosomes initiate pre-metastatic niche formation in the liver. Nat Cell Biol. 2015;17(6):816-26.

23. Barile L, Vassalli G. Exosomes: therapy delivery tools and biomarkers of diseases. Pharmacol Ther. 2017;174:63-78.

24. Wang M, Ji S, Shao G, Zhang J, Zhao K, Wang Z, Wu A. Effect of exosome biomarkers for diagnosis and prognosis of breast cancer patients. Clin Transl Oncol. 2018:20(7):906-11.

25. Wang H, Lu Z, Zhao X. Tumorigenesis, diagnosis, and therapeutic potential of exosomes in liver cancer. J Hematol Oncol. 2019;12(1):133.

26. Zheng J, Hernandez JM, Doussot A, Bojmar L, Zambirinis CP, Costa-Silva B, van Beek E, Mark MT, Molina H, Askan G, et al. Extracellular matrix proteins and carcinoembryonic antigen-related cell adhesion molecules characterize pancreatic duct fluid exosomes in patients with pancreatic cancer. HPB (Oxford). 2018;20(7):597-604.

27. Melo SA, Luecke LB, Kahlert C, Fernandez AF, Gammon ST, Kaye J, LeBleu VS, Mittendorf EA, Weitz J, Rahbari N, et al. Glypican-1 identifies cancer exosomes and detects early pancreatic cancer. Nature. 2015:523(7559):177-82.

28. Su D, Tsai HI, Xu Z, Yan F, Wu Y, Xiao Y, Liu X, Wu Y, Parvanian S, Zhu W, et al. Exosomal PD-L1 functions as an immunosuppressant to promote wound healing. J Extracell Vesicles. 2019;9(1):1709262.

29. Ariston Gabriel AN, Wang F, Jiao Q, Yvette U, Yang X, Al-Ameri SA, Du L, Wang YS, Wang $C$. The involvement of exosomes in the diagnosis and treatment of pancreatic cancer. Mol Cancer. 2020;19(1):132.

30. Han C, Kang H, Yi J, Kang M, Lee H, Kwon Y, Jung J, Lee J, Park J. Singlevesicle imaging and co-localization analysis for tetraspanin profiling of individual extracellular vesicles. J Extracell Vesicles. 2021;10(3):e12047.

31. Taylor DD, Gercel-Taylor C. The origin, function, and diagnostic potential of RNA within extracellular vesicles present in human biological fluids. Front Genet. 2013;4:142.

32. Hessvik NP, Llorente A. Current knowledge on exosome biogenesis and release. Cell Mol Life Sci. 2018;75(2):193-208.

33. van Niel G, D'Angelo G, Raposo G. Shedding light on the cell biology of extracellular vesicles. Nat Rev Mol Cell Biol. 2018;19(4):213-28.

34. Kahlert C, Kalluri R. Exosomes in tumor microenvironment influence cancer progression and metastasis. J Mol Med (Berl). 2013;91(4):431-7. 
35. Ciardiello C, Cavallini L, Spinelli C, Yang J, Reis-Sobreiro M, de Candia P, Minciacchi VR, Di Vizio D. Focus on extracellular vesicles: new frontiers of cell-to-cell communication in cancer. Int J Mol Sci. 2016;17(2):175.

36. Bebelman MP, Smit MJ, Pegtel DM, Baglio SR. Biogenesis and function of extracellular vesicles in cancer. Pharmacol Ther. 2018;188:1-11.

37. Mulcahy LA, Pink RC, Carter DR. Routes and mechanisms of extracellular vesicle uptake. J Extracell Vesicles. 2014;3:24641.

38. Tian T, Zhu YL, Zhou YY, Liang GF, Wang YY, Hu FH, Xiao ZD. Exosome uptake through clathrin-mediated endocytosis and macropinocytosis and mediating miR-21 delivery. J Biol Chem. 2014;289(32):22258-67.

39. Feng D, Zhao WL, Ye YY, Bai XC, Liu RQ, Chang LF, Zhou Q, Sui SF. Cellular internalization of exosomes occurs through phagocytosis. Traffic. 2010;11(5):675-87.

40. Kamerkar S, LeBleu VS, Sugimoto H, Yang S, Ruivo CF, Melo SA, Lee JJ, Kalluri R. Exosomes facilitate therapeutic targeting of oncogenic KRAS in pancreatic cancer. Nature. 2017:546(7659):498-503.

41. Eguchi S, Takefuji M, Sakaguchi T, Ishihama S, Mori Y, Tsuda T, Takikawa T, Yoshida T, Ohashi K, Shimizu Y, et al. Cardiomyocytes capture stem cellderived, anti-apoptotic microRNA-214 via clathrin-mediated endocytosis in acute myocardial infarction. J Biol Chem. 2019;294(31):11665-74.

42. Parolini I, Federici C, Raggi C, Lugini L, Palleschi S, De Milito A, Coscia C, lessi E, Logozzi M, Molinari A, et al. Microenvironmental $\mathrm{pH}$ is a key factor for exosome traffic in tumor cells. J Biol Chem. 2009;284(49):34211-22.

43. Corbeil D, Santos MF, Karbanova J, Kurth T, Rappa G, Lorico A. Uptake and fate of extracellular membrane vesicles: nucleoplasmic reticulumassociated late endosomes as a new gate to intercellular communication. Cells. 2020;9(9):1931.

44. Wallis R, Josipovic N, Mizen H, Robles-Tenorio A, Tyler EJ, Papantonis A, Bishop CL. Isolation methodology is essential to the evaluation of the extracellular vesicle component of the senescence-associated secretory phenotype. J Extracell Vesicles. 2021;10(4):e12041.

45. Ding L, Yang X, Gao Z, Effah CY, Zhang X, Wu Y, Qu L. A holistic review of the state-of-the-art microfluidics for exosome separation: an overview of the current status, existing obstacles, and future outlook. Small. 2021. https://doi.org/10.1002/smll.202007174.

46. Thery C, Witwer KW, Aikawa E, Alcaraz MJ, Anderson JD, Andriantsitohaina R, Antoniou A, Arab T, Archer F, Atkin-Smith GK, et al. Minimal information for studies of extracellular vesicles 2018 (MISEV2018): a position statement of the International Society for Extracellular Vesicles and update of the MISEV2014 guidelines. J Extracell Vesicles. 2018:7(1):1535750.

47. Lin S, Yu Z, Chen D, Wang Z, Miao J, Li Q, Zhang D, Song J, Cui D. Progress in microfluidics-based exosome separation and detection technologies for diagnostic applications. Small. 2020;16(9):e1903916.

48. Zhang K, Yue Y, Wu S, Liu W, Shi J, Zhang Z. Rapid capture and nondestructive release of extracellular vesicles using aptamer-based magnetic isolation. ACS Sens. 2019;4(5):1245-51.

49. Yang F, Liao X, Tian Y, Li G. Exosome separation using microfluidic systems: size-based, immunoaffinity-based and dynamic methodologies. Biotechnol J. 2017;12(4):1600699.

50. Liga A, Vliegenthart AD, Oosthuyzen W, Dear JW, KersaudyKerhoas M. Exosome isolation: a microfluidic road-map. Lab Chip. 2015;15(11):2388-94.

51. Jiang Y, Shi M, Liu Y, Wan S, Cui C, Zhang L, Tan W. Aptamer/AuNP biosensor for colorimetric profiling of exosomal proteins. Angew Chem Int Ed Engl. 2017;56(39):11916-20.

52. Zhao G, Li H, Guo Q, Zhou A, Wang X, Li P, Zhang S. Exosomal Sonic Hedgehog derived from cancer-associated fibroblasts promotes proliferation and migration of esophageal squamous cell carcinoma. Cancer Med. 2020;9(7):2500-13

53. Zhang Q, Len TY, Zhang SX, Zhao QH, Yang LH. Exosomes transferring long non-coding RNA FAL1 to regulate ovarian cancer metastasis through the PTEN/AKT signaling pathway. Eur Rev Med Pharmacol Sci. 2020;24(21):10921.

54. Plebanek MP, Angeloni NL, Vinokour E, Li J, Henkin A, Martinez-Marin D, Filleur S, Bhowmick R, Henkin J, Miller SD, et al. Pre-metastatic cancer exosomes induce immune surveillance by patrolling monocytes at the metastatic niche. Nat Commun. 2017;8(1):1319.

55. Lee HY, Chen CK, Ho CM, Lee SS, Chang CY, Chen KJ, Jou YS. EIF3C-enhanced exosome secretion promotes angiogenesis and tumorigenesis of human hepatocellular carcinoma. Oncotarget. 2018;9(17):13193-205

56. Qu L, Ding J, Chen C, Wu ZJ, Liu B, Gao Y, Chen W, Liu F, Sun W, Li XF, et al. Exosome-transmitted IncARSR promotes sunitinib resistance in renal cancer by acting as a competing endogenous RNA. Cancer Cell. 2016;29(5):653-68.

57. Robless EE, Howard JA, Casari I, Falasca M. Exosomal long non-coding RNAs in the diagnosis and oncogenesis of pancreatic cancer. Cancer Lett. 2021:501:55-65.

58. Sun W, Ren Y, Lu Z, Zhao X. The potential roles of exosomes in pancreatic cancer initiation and metastasis. Mol Cancer. 2020;19(1):135.

59. Moeng S, Son SW, Lee JS, Lee HY, Kim TH, Choi SY, Kuh HJ, Park JK. Extracellular vesicles (EVs) and pancreatic cancer: from the role of EVs to the interference with EV-mediated reciprocal communication. Biomedicines. 2020;8(8):267

60. Fang Z, Xu J, Zhang B, Wang W, Liu J, Liang C, Hua J, Meng Q, Yu X, Shi S. The promising role of noncoding RNAs in cancer-associated fibroblasts: an overview of current status and future perspectives. J Hematol Oncol. 2020;13(1):154

61. Li Z, Tao Y, Wang X, Jiang $P$, Li J, Peng M, Zhang X, Chen $K$, Liu H, Zhen $P$, et al. Tumor-secreted exosomal miR-222 promotes tumor progression via regulating P27 expression and re-localization in pancreatic cancer. Cell Physiol Biochem. 2018;51(2):610-29.

62. Yin Z, Ma T, Huang B, Lin L, Zhou Y, Yan J, Zou Y, Chen S. Macrophagederived exosomal microRNA-501-3p promotes progression of pancreatic ductal adenocarcinoma through the TGFBR3-mediated TGF-beta signaling pathway. J Exp Clin Cancer Res. 2019;38(1):310.

63. Li M, Guo H, Wang Q, Chen K, Marko K, Tian X, Yang Y. Pancreatic stellate cells derived exosomal miR-5703 promotes pancreatic cancer by downregulating CMTM4 and activating PI3K/Akt pathway. Cancer Lett. 2020:490:20-30.

64. Sun H, Shi K, Qi K, Kong H, Zhang J, Dai S, Ye W, Deng T, He Q, Zhou M. Natural killer cell-derived exosomal miR-3607-3p inhibits pancreatic cancer progression by targeting IL-26. Front Immunol. 2019;10:2819.

65. Shang S, Wang J, Chen S, Tian R, Zeng H, Wang L, Xia M, Zhu H, Zuo C. Exosomal miRNA-1231 derived from bone marrow mesenchymal stem cells inhibits the activity of pancreatic cancer. Cancer Med. 2019;8(18):7728-40.

66. Wu DM, Wen X, Han XR, Wang S, Wang YJ, Shen M, Fan SH, Zhang ZF, Shan Q Li MQ et al. Bone marrow mesenchymal stem cell-derived exosomal microRNA-126-3p inhibits pancreatic cancer development by targeting ADAM9. Mol Ther Nucleic Acids. 2019;16:229-45.

67. Hosein AN, Brekken RA, Maitra A. Pancreatic cancer stroma: an update on therapeutic targeting strategies. Nat Rev Gastroenterol Hepatol. 2020;17(8):487-505.

68. Shang D, Xie C, Hu J, Tan J, Yuan Y, Liu Z, Yang Z. Pancreatic cancer cell-derived exosomal microRNA-27a promotes angiogenesis of human microvascular endothelial cells in pancreatic cancer via BTG2. J Cell Mol Med. 2020;24(1):588-604

69. Guo Z, Wang X, Yang Y, Chen W, Zhang K, Teng B, Huang C, Zhao Q, Qiu Z. Hypoxic tumor-derived exosomal long noncoding RNA UCA1 promotes angiogenesis via miR-96-5p/AMOTL2 in pancreatic cancer. Mol Ther Nucleic Acids. 2020:22:179-95.

70. Steinbichler TB, Dudas J, Riechelmann H, Skvortsova II. The role of exosomes in cancer metastasis. Semin Cancer Biol. 2017:44:170-81.

71. Kong F, Li L, Wang G, Deng X, Li Z, Kong X. VDR signaling inhibits cancer-associated-fibroblasts' release of exosomal miR-10a-5p and limits their supportive effects on pancreatic cancer cells. Gut. 2019;68(5):950-1.

72. Ali S, Suresh R, Banerjee S, Bao B, Xu Z, Wilson J, Philip PA, Apte M, Sarkar $\mathrm{FH}$. Contribution of microRNAs in understanding the pancreatic tumor microenvironment involving cancer associated stellate and fibroblast cells. Am J Cancer Res. 2015;5(3):1251-64.

73. Takikawa T, Masamune A, Yoshida N, Hamada S, Kogure T, Shimosegawa T. exosomes derived from pancreatic stellate cells: microRNA signature and effects on pancreatic cancer cells. Pancreas. 2017:46(1):19-27.

74. Yin Z, Zhou Y, Ma T, Chen S, Shi N, Zou Y, Hou B, Zhang C. Down-regulated IncRNA SBF2-AS1 in M2 macrophage-derived exosomes elevates miR-122-5p to restrict XIAP, thereby limiting pancreatic cancer development. J Cell Mol Med. 2020;24(9):5028-38. 
75. Takahashi K, Ota Y, Kogure T, Suzuki Y, Iwamoto H, Yamakita K, Kitano Y, Fujii S, Haneda M, Patel T, et al. Circulating extracellular vesicle-encapsulated HULC is a potential biomarker for human pancreatic cancer. Cancer Sci. 2020;111(1):98-111.

76. Wang X, Li H, Lu X, Wen C, Huo Z, Shi M, Tang X, Chen H, Peng C, Fang Y, et al. Melittin-induced long non-coding RNA NONHSAT105177 inhibits proliferation and migration of pancreatic ductal adenocarcinoma. Cell Death Dis. 2018;9(10):940.

77. Li Z, Jiang P, Li J, Peng M, Zhao X, Zhang X, Chen K, Zhang Y, Liu H, Gan L, et al. Tumor-derived exosomal Inc-Sox2ot promotes EMT and stemness by acting as a ceRNA in pancreatic ductal adenocarcinoma. Oncogene. 2018;37(28):3822-38.

78. Li Z, Yanfang $W$, Li J, Jiang $P$, Peng $T$, Chen $K$, Zhao $X$, Zhang $Y$, Zhen $P$, Zhu J, et al. Tumor-released exosomal circular RNA PDE8A promotes invasive growth via the miR-338/MACC1/MET pathway in pancreatic cancer. Cancer Lett. 2018:432:237-50.

79. Li J, Li Z, Jiang P, Peng M, Zhang X, Chen K, Liu H, Bi H, Liu X, Li X. Circular RNA IARS (circ-IARS) secreted by pancreatic cancer cells and located within exosomes regulates endothelial monolayer permeability to promote tumor metastasis. J Exp Clin Cancer Res. 2018;37(1):177.

80. Pastushenko I, Blanpain C. EMT transition states during tumor progression and metastasis. Trends Cell Biol. 2019;29(3):212-26.

81. Dongre A, Weinberg RA. New insights into the mechanisms of epithelial-mesenchymal transition and implications for cancer. Nat Rev Mol Cell Biol. 2019;20(2):69-84.

82. Diepenbruck M, Christofori G. Epithelial-mesenchymal transition (EMT) and metastasis: yes, no, maybe? Curr Opin Cell Biol. 2016;43:7-13.

83. Greening DW, Gopal SK, Mathias RA, Liu L, Sheng J, Zhu HJ, Simpson RJ. Emerging roles of exosomes during epithelial-mesenchymal transition and cancer progression. Semin Cell Dev Biol. 2015;40:60-71.

84. Kim H, Lee S, Shin E, Seong KM, Jin YW, Youn H, Youn B. The emerging roles of exosomes as EMT regulators in cancer. Cells. 2020;9(4):861.

85. Wu M, Tan X, Liu P, Yang Y, Huang Y, Liu X, Meng X, Yu B, Wu Y, Jin H. Role of exosomal microRNA-125b-5p in conferring the metastatic phenotype among pancreatic cancer cells with different potential of metastasis. Life Sci. 2020;255:117857.

86. Wang X, Luo G, Zhang K, Cao J, Huang C, Jiang T, Liu B, Su L, Qiu Z. Hypoxic tumor-derived exosomal miR-301a mediates M2 macrophage polarization via PTEN/PI3Kgamma to promote pancreatic cancer metastasis. Cancer Res. 2018;78(16):4586-98.

87. Gehrmann U, Naslund TI, Hiltbrunner S, Larssen P, Gabrielsson S. Harnessing the exosome-induced immune response for cancer immunotherapy. Semin Cancer Biol. 2014;28:58-67.

88. Robbins PD, Morelli AE. Regulation of immune responses by extracellular vesicles. Nat Rev Immunol. 2014;14(3):195-208.

89. Sharma P, Diergaarde B, Ferrone S, Kirkwood JM, Whiteside TL. Melanoma cell-derived exosomes in plasma of melanoma patients suppress functions of immune effector cells. Sci Rep. 2020;10(1):92.

90. Cox MJ, Lucien F, Sakemura R, Boysen JC, Kim Y, Horvei P, Manriquez Roman C, Hansen MJ, Tapper EE, Siegler EL, et al. Leukemic extracellular vesicles induce chimeric antigen receptor T cell dysfunction in chronic lymphocytic leukemia. Mol Ther. 2021;29(4):1529-40.

91. Czystowska-Kuzmicz M, Sosnowska A, Nowis D, Ramji K, Szajnik M, Chlebowska-Tuz J, Wolinska E, Gaj P, Grazul M, Pilch Z, et al. Small extracellular vesicles containing arginase-1 suppress T-cell responses and promote tumor growth in ovarian carcinoma. Nat Commun. 2019;10(1):3000.

92. Ludwig S, Floros T, Theodoraki MN, Hong CS, Jackson EK, Lang S, Whiteside TL. Suppression of lymphocyte functions by plasma exosomes correlates with disease activity in patients with head and neck cancer. Clin Cancer Res. 2017;23(16):4843-54.

93. Tucci M, Passarelli A, Mannavola F, Felici C, Stucci LS, Cives M, Silvestris F. Immune system evasion as hallmark of melanoma progression: the role of dendritic cells. Front Oncol. 2019;9:1148.

94. Zhou M, Chen J, Zhou L, Chen W, Ding G, Cao L. Pancreatic cancer derived exosomes regulate the expression of TLR4 in dendritic cells via miR-203. Cell Immunol. 2014;292(1-2):65-9.

95. Ding G, Zhou L, Qian Y, Fu M, Chen J, Chen J, Xiang J, Wu Z, Jiang G, Cao L. Pancreatic cancer-derived exosomes transfer miRNAs to dendritic cells and inhibit RFXAP expression via miR-212-3p. Oncotarget. 2015:6(30):29877-88.
96. Housman G, Byler S, Heerboth S, Lapinska K, Longacre M, Snyder $\mathrm{N}$, Sarkar S. Drug resistance in cancer: an overview. Cancers (Basel). 2014;6(3):1769-92.

97. Chen WX, Liu XM, Lv MM, Chen L, Zhao JH, Zhong SL, Ji MH, Hu Q, Luo $\mathrm{Z}$, Wu JZ, et al. Exosomes from drug-resistant breast cancer cells transmit chemoresistance by a horizontal transfer of microRNAs. PLOS ONE. 2014;9(4):e95240.

98. Hu Y, Yan C, Mu L, Huang K, Li X, Tao D, Wu Y, Qin J. Fibroblast-derived exosomes contribute to chemoresistance through priming cancer stem cells in colorectal cancer. PLoS ONE. 2015;10(5):e0125625.

99. Yang Z, Zhao N, Cui J, Wu H, Xiong J, Peng T. Exosomes derived from cancer stem cells of gemcitabine-resistant pancreatic cancer cells enhance drug resistance by delivering miR-210. Cell Oncol (Dordr). 2020:43(1):123-36.

100. Fang Y, Zhou W, Rong Y, Kuang T, Xu X, Wu W, Wang D, Lou W. Exosomal miRNA-106b from cancer-associated fibroblast promotes gemcitabine resistance in pancreatic cancer. Exp Cell Res. 2019;383(1):111543.

101. Binenbaum Y, Fridman E, Yaari Z, Milman N, Schroeder A, Ben David G, Shlomi T, Gil Z. Transfer of miRNA in macrophage-derived exosomes induces drug resistance in pancreatic adenocarcinoma. Cancer Res. 2018;78(18):5287-99.

102. Mikamori M, Yamada D, Eguchi H, Hasegawa S, Kishimoto T, Tomimaru Y, Asaoka T, Noda T, Wada H, Kawamoto K, et al. MicroRNA-155 controls exosome synthesis and promotes gemcitabine resistance in pancreatic ductal adenocarcinoma. Sci Rep. 2017:7:42339.

103. Patel GK, Khan MA, Bhardwaj A, Srivastava SK, Zubair H, Patton MC, Singh S, Khushman M, Singh AP. Exosomes confer chemoresistance to pancreatic cancer cells by promoting ROS detoxification and miR155-mediated suppression of key gemcitabine-metabolising enzyme, DCK. Br J Cancer. 2017;116(5):609-19.

104. Neoptolemos JP, Kleeff J, Michl P, Costello E, Greenhalf W, Palmer DH. Therapeutic developments in pancreatic cancer: current and future perspectives. Nat Rev Gastroenterol Hepatol. 2018;15(6):333-48.

105. Jiang MJ, Chen YY, Dai JJ, Gu DN, Mei Z, Liu FR, Huang Q, Tian L. Dying tumor cell-derived exosomal miR-194-5p potentiates survival and repopulation of tumor repopulating cells upon radiotherapy in pancreatic cancer. Mol Cancer. 2020;19(1):68.

106. Chen YY, Jiang MJ, Tian L. Analysis of exosomal circRNAs upon irradiation in pancreatic cancer cell repopulation. BMC Med Genom. 2020;13(1):107.

107. Soreide K. Sweet predictions speak volumes for early detection of pancreatic cancer. Gastroenterology. 2018;155(2):265-8.

108. Pelzer U, Hilbig A, Sinn M, Stieler J, Bahra M, Dorken B, Riess H. Value of carbohydrate antigen 19-9 in predicting response and therapy control in patients with metastatic pancreatic cancer undergoing first-line therapy. Front Oncol. 2013;3:155.

109. Humphris JL, Chang DK, Johns AL, Scarlett CJ, Pajic M, Jones MD, Colvin EK, Nagrial A, Chin VT, Chantrill LA, et al. The prognostic and predictive value of serum CA199 in pancreatic cancer. Ann Oncol. 2012;23(7):1713-22.

110. Ballehaninna UK, Chamberlain RS. The clinical utility of serum CA 19-9 in the diagnosis, prognosis and management of pancreatic adenocarcinoma: an evidence based appraisal. J Gastrointest Oncol. 2012;3(2):105-19.

111. Kahroba H, Hejazi MS, Samadi N. Exosomes: from carcinogenesis and metastasis to diagnosis and treatment of gastric cancer. Cell Mol Life Sci. 2019;76(9):1747-58.

112. Fitts CA, Ji N, Li Y, Tan C. Exploiting exosomes in cancer liquid biopsies and drug delivery. Adv Healthc Mater. 2019;8(6):e1801268.

113. Thind A, Wilson C. Exosomal miRNAs as cancer biomarkers and therapeutic targets. J Extracell Vesicles. 2016;5:31292.

114. Salehi M, Sharifi M. Exosomal miRNAs as novel cancer biomarkers: challenges and opportunities. J Cell Physiol. 2018;233(9):6370-80.

115. Yee NS, Zhang S, He HZ, Zheng SY. Extracellular vesicles as potentia biomarkers for early detection and diagnosis of pancreatic cancer. Biomedicines. 2020;8(12):581.

116. Wu L, Zhou WB, Zhou J, Wei Y, Wang HM, Liu XD, Chen XC, Wang W, Ye L, Yao LC, et al. Circulating exosomal microRNAs as novel potential detection biomarkers in pancreatic cancer. Oncol Lett. 2020;20(2):1432-40. 
117. Pu X, Ding G, Wu M, Zhou S, Jia S, Cao L. Elevated expression of exosomal microRNA-21 as a potential biomarker for the early diagnosis of pancreatic cancer using a tethered cationic lipoplex nanoparticle biochip. Oncol Lett. 2020;19(3):2062-70.

118. Goto T, Fujiya M, Konishi H, Sasajima J, Fujibayashi S, Hayashi A, Utsumi T, Sato H, Iwama T, Ijiri M, et al. An elevated expression of serum exosomal microRNA-191, - 21, -451a of pancreatic neoplasm is considered to be efficient diagnostic marker. BMC Cancer. 2018;18(1):116.

119. Que R, Ding G, Chen J, Cao L. Analysis of serum exosomal microRNAs and clinicopathologic features of patients with pancreatic adenocarcinoma. World J Surg Oncol. 2013;11:219.

120. Lai X, Wang M, McElyea SD, Sherman S, House M, Korc M. A microRNA signature in circulating exosomes is superior to exosomal glypican-1 levels for diagnosing pancreatic cancer. Cancer Lett. 2017;393:86-93.

121. Xu YF, Hannafon BN, Zhao YD, Postier RG, Ding WQ. Plasma exosome miR-196a and miR-1246 are potential indicators of localized pancreatic cancer. Oncotarget. 2017;8(44):77028-40.

122. Takahasi K, linuma H, Wada K, Minezaki S, Kawamura S, Kainuma M, Ikeda Y, Shibuya M, Miura F, Sano K. Usefulness of exosome-encapsulated microRNA-451a as a minimally invasive biomarker for prediction of recurrence and prognosis in pancreatic ductal adenocarcinoma. J Hepatobiliary Pancreat Sci. 2018;25(2):155-61.

123. Ideno N, Mori Y, Nakamura M, Ohtsuka T. Early Detection of pancreatic cancer: role of biomarkers in pancreatic fluid samples. Diagnostics (Basel). 2020;10(12):1056.

124. Kawamura S, linuma H, Wada K, Takahashi K, Minezaki S, Kainuma M, Shibuya M, Miura F, Sano K. Exosome-encapsulated microRNA-4525, microRNA-451a and microRNA-21 in portal vein blood is a highsensitive liquid biomarker for the selection of high-risk pancreatic ductal adenocarcinoma patients. J Hepatobiliary Pancreat Sci. 2019;26(2):63-72.

125. Nakamura S, Sadakari Y, Ohtsuka T, Okayama T, Nakashima Y, Gotoh Y, Saeki K, Mori Y, Nakata K, Miyasaka Y, et al. Pancreatic juice exosomal MicroRNAs as biomarkers for detection of pancreatic ductal adenocarcinoma. Ann Surg Oncol. 2019;26(7):2104-11.

126. Machida T, Tomofuji T, Maruyama T, Yoneda T, Ekuni D, Azuma T, Miyai H, Mizuno H, Kato H, Tsutsumi K, et al. miR1246 and miR4644 in salivary exosome as potential biomarkers for pancreatobiliary tract cancer. Oncol Rep. 2016;36(4):2375-81.

127. Madhavan B, Yue S, Galli U, Rana S, Gross W, Muller M, Giese NA, Kalthoff H, Becker T, Buchler MW, et al. Combined evaluation of a panel of protein and miRNA serum-exosome biomarkers for pancreatic cancer diagnosis increases sensitivity and specificity. Int J Cancer. 2015;136(11):2616-27.

128. Yang Z, LaRiviere MJ, Ko J, Till JE, Christensen T, Yee SS, Black TA, Tien K, Lin A, Shen $\mathrm{H}$, et al. A multianalyte panel consisting of extracellular vesicle miRNAs and mRNAs, cfDNA, and CA19-9 shows utility for diagnosis and staging of pancreatic ductal adenocarcinoma. Clin Cancer Res. 2020;26(13):3248-58.

129. Yu S, Li Y, Liao Z, Wang Z, Wang Z, Li Y, Qian L, Zhao J, Zong H, Kang $B$, et al. Plasma extracellular vesicle long RNA profiling identifies a diagnostic signature for the detection of pancreatic ductal adenocarcinoma. Gut. 2020;69(3):540-50.

130. Zhou S, Hu T, Han G, Wu Y, Hua X, Su J, Jin W, Mou Y, Mou X, Li Q, et al. Accurate cancer diagnosis and stage monitoring enabled by comprehensive profiling of different types of exosomal biomarkers: surface proteins and miRNAs. Small. 2020;16(48):e2004492.

131. Zou X, Wei J, Huang Z, Zhou X, Lu Z, Zhu W, Miao Y. Identification of a six-miRNA panel in serum benefiting pancreatic cancer diagnosis. Cancer Med. 2019;8(6):2810-22.

132. Ko J, Bhagwat N, Yee SS, Ortiz N, Sahmoud A, Black T, Aiello NM, McKenzie L, O'Hara M, Redlinger C, et al. Combining machine learning and nanofluidic technology to diagnose pancreatic cancer using exosomes. ACS Nano. 2017;11(11):11182-93.

133. Taller D, Richards K, Slouka Z, Senapati S, Hill R, Go DB, Chang HC. Onchip surface acoustic wave lysis and ion-exchange nanomembrane detection of exosomal RNA for pancreatic cancer study and diagnosis. Lab Chip. 2015;15(7):1656-66.

134. Ko J, Bhagwat N, Black T, Yee SS, Na YJ, Fisher S, Kim J, Carpenter EL, Stanger BZ, Issadore D. miRNA profiling of magnetic nanopore-isolated extracellular vesicles for the diagnosis of pancreatic cancer. Cancer Res. 2018;78(13):3688-97.

135. Pang Y, Wang C, Lu L, Wang C, Sun Z, Xiao R. Dual-SERS biosensor for one-step detection of microRNAs in exosome and residual plasma of blood samples for diagnosing pancreatic cancer. Biosens Bioelectron. 2019;130:204-13.

136. Kumar SR, Kimchi ET, Manjunath Y, Gajagowni S, Stuckel AJ, Kaifi JT. RNA cargos in extracellular vesicles derived from blood serum in pancreas associated conditions. Sci Rep. 2020;10(1):2800.

137. Seimiya T, Otsuka M, Iwata T, Shibata C, Tanaka E, Suzuki T, Koike K. Emerging roles of exosomal circular RNAs in cancer. Front Cell Dev Biol. 2020;8:568366.

138. Guo X, Tan W, Wang C. The emerging roles of exosomal circRNAs in diseases. Clin Transl Oncol. 2021;23(6):1020-33.

139. Kitagawa T, Taniuchi K, Tsuboi M, Sakaguchi M, Kohsaki T, Okabayashi T, Saibara T. Circulating pancreatic cancer exosomal RNAs for detection of pancreatic cancer. Mol Oncol. 2019;13(2):212-27.

140. Hu J, Sheng Y, Kwak KJ, Shi J, Yu B, Lee LJ. A signal-amplifiable biochip quantifies extracellular vesicle-associated RNAs for early cancer detection. Nat Commun. 2017;8(1):1683.

141. Ding Y, Cao F, Sun H, Wang Y, Liu S, Wu Y, Cui Q, Mei W, Li F. Exosomes derived from human umbilical cord mesenchymal stromal cells deliver exogenous miR-145-5p to inhibit pancreatic ductal adenocarcinoma progression. Cancer Lett. 2019;442:351-61.

142. Su MJ, Aldawsari H, Amiji M. Pancreatic cancer cell exosome-mediated macrophage reprogramming and the role of MicroRNAs 155 and $125 \mathrm{~b} 2$ transfection using nanoparticle delivery systems. Sci Rep. 2016;6:30110.

143. O'Brien K, Breyne K, Ughetto S, Laurent LC, Breakefield XO. RNA delivery by extracellular vesicles in mammalian cells and its applications. Nat Rev Mol Cell Biol. 2020:21(10):585-606.

144. Escude Martinez de Castilla P, Tong L, Huang C, Marios Sofias A, Pastorin G, Chen X, Storm G, Schiffelers RM, Wang JW. Extracellular vesicles as a drug delivery system: a systematic review of preclinical studies. Adv Drug Deliv Rev. 2021;175:113801.

145. Melzer C, Rehn V, Yang Y, Bahre H, von der Ohe J, Hass R. Taxol-loaded MSC-derived exosomes provide a therapeutic vehicle to target metastatic breast cancer and other carcinoma cells. Cancers (Basel). 2019;11(6):798

146. Yang Z, Shi J, Xie J, Wang Y, Sun J, Liu T, Zhao Y, Zhao X, Wang X, $M a Y$, et al. Large-scale generation of functional mRNA-encapsulating exosomes via cellular nanoporation. Nat Biomed Eng. 2020;4(1):69-83.

147. Ye Z, Zhang T, He W, Jin H, Liu C, Yang Z, Ren J. Methotrexate-loaded extracellular vesicles functionalized with therapeutic and targeted peptides for the treatment of glioblastoma multiforme. ACS Appl Mater Interfaces. 2018;10(15):12341-50.

148. Kim G, Kim M, Lee Y, Byun JW, Hwang DW, Lee M. Systemic delivery of microRNA-21 antisense oligonucleotides to the brain using T7-peptide decorated exosomes. J Control Release. 2020;317:273-81.

149. Jia G, Han Y, An Y, Ding Y, He C, Wang X, Tang Q. NRP-1 targeted and cargo-loaded exosomes facilitate simultaneous imaging and therapy of glioma in vitro and in vivo. Biomaterials. 2018;178:302-16.

150. Wang P, Wang H, Huang Q, Peng C, Yao L, Chen H, Qiu Z, Wu Y, Wang L, Chen W. Exosomes from M1-polarized macrophages enhance paclitaxel antitumor activity by activating macrophages-mediated inflammation. Theranostics. 2019:9(6):1714-27.

151. Yang T, Fogarty B, LaForge B, Aziz S, Pham T, Lai L, Bai S. Delivery of small interfering RNA to inhibit vascular endothelial growth factor in zebrafish using natural brain endothelia cell-secreted exosome nanovesicles for the treatment of brain cancer. AAPS J. 2017;19(2):475-86.

152. Pi F, Binzel DW, Lee TJ, Li Z, Sun M, Rychahou P, Li H, Haque F, Wang S, Croce CM, et al. Nanoparticle orientation to control RNA loading and ligand display on extracellular vesicles for cancer regression. Nat Nanotechnol. 2018;13(1):82-9.

153. Liao W, Du Y, Zhang C, Pan F, Yao Y, Zhang T, Peng Q. Exosomes: the next generation of endogenous nanomaterials for advanced drug delivery and therapy. Acta Biomater. 2019;86:1-14. 
154. Ha D, Yang N, Nadithe V. Exosomes as therapeutic drug carriers and delivery vehicles across biological membranes: current perspectives and future challenges. Acta Pharm Sin B. 2016;6(4):287-96.

155. Ferguson SW, Nguyen J. Exosomes as therapeutics: the implications of molecular composition and exosomal heterogeneity. J Control Release. 2016;228:179-90.

156. Zhou Y, Zhou W, Chen X, Wang Q, Li C, Chen Q, Zhang Y, Lu Y, Ding X, Jiang $C$. Bone marrow mesenchymal stem cells-derived exosomes for penetrating and targeted chemotherapy of pancreatic cancer. Acta Pharm Sin B. 2020;10(8):1563-75.
157. Mendt M, Kamerkar S, Sugimoto H, McAndrews KM, Wu CC, Gagea M, Yang S, Blanko EVR, Peng Q, Ma X, et al. Generation and testing of clinical-grade exosomes for pancreatic cancer. JCl Insight. 2018;3(8):e99263.

\section{Publisher's Note}

Springer Nature remains neutral with regard to jurisdictional claims in published maps and institutional affiliations.
Ready to submit your research? Choose BMC and benefit from:

- fast, convenient online submission

- thorough peer review by experienced researchers in your field

- rapid publication on acceptance

- support for research data, including large and complex data types

- gold Open Access which fosters wider collaboration and increased citations

- maximum visibility for your research: over 100M website views per year

At BMC, research is always in progress.

Learn more biomedcentral.com/submissions 